\title{
Parameterizing the competition between homogeneous and heterogeneous freezing in cirrus cloud formation - monodisperse ice nuclei
}

\author{
D. Barahona ${ }^{1}$ and A. Nenes ${ }^{1,2}$ \\ ${ }^{1}$ School of Chemical and Biomolecular Engineering, Georgia Institute of Technology, USA \\ ${ }^{2}$ School of Earth and Atmospheric Sciences, Georgia Institute of Technology, USA
}

Received: 30 June 2008 - Published in Atmos. Chem. Phys. Discuss.: 18 August 2008

Revised: 8 December 2008 - Accepted: 8 December 2008 - Published: 16 January 2009

\begin{abstract}
We present a parameterization of cirrus cloud formation that computes the ice crystal number and size distribution under the presence of homogeneous and heterogeneous freezing. The parameterization is very simple to apply and is derived from the analytical solution of the cloud parcel equations, assuming that the ice nuclei population is monodisperse and chemically homogeneous. In addition to the ice distribution, an analytical expression is provided for the limiting ice nuclei number concentration that suppresses ice formation from homogeneous freezing. The parameterization is evaluated against a detailed numerical parcel model, and reproduces numerical simulations over a wide range of conditions with an average error of $6 \pm 33 \%$. The parameterization also compares favorably against other formulations that require some form of numerical integration.
\end{abstract}

\section{Introduction}

Cirrus clouds are key components of climate and can have a major impact on its radiative balance (Liou, 1986; Hartmann et al., 2001; Lohmann et al., 2004). They can be affected by anthropogenic activities such as aircraft emissions in the upper troposphere (Seinfeld, 1998; Penner et al., 1999; Minnis, 2004; Stuber et al., 2006; Kärcher et al., 2007), and from long range transport of pollution and dust (Sassen et al., 2003; Fridlind et al., 2004). When studying ice-cloudclimate interactions, the key cloud properties that need to be computed are ice crystal concentration distribution, and

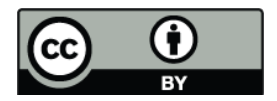

Correspondence to: A. Nenes (nenes@eas.gatech.edu) ice water content (e.g. Lin et al., 2002); in large-scale models such parameters are either prescribed or computed with a parameterization. Due to the limited understanding of the physics behind ice nucleation, and the diversity and complexity of interactions between atmospheric particles during cirrus formation and evolution, the anthropogenic effect on cirrus clouds remains a major source of uncertainty in climate change predictions (e.g. Baker and Peter, 2008).

Cirrus can form by either homogeneous or heterogeneous freezing. Homogeneous freezing occurs spontaneously from temperature and density fluctuations within a supercooled liquid phase (Pruppacher and Klett, 1997); whether it happens however largely depends on the temperature, droplet volume, and water activity within the liquid phase (Chen et al., 2000; Koop et al., 2000; Cziczo and Abbatt, 2001; Lin et al., 2002). The rate of formation of ice germs by homogeneous nucleation has been extensively studied and can be computed using a number of relationships based on experiments and theory (e.g. DeMott et al., 1994; Khvorostyanov and Sassen, 1998; Koop et al., 2000; Tabazadeh et al., 2000). Most cirrus clouds form at conditions favorable for homogeneous freezing, which is believed to be the primary mechanism of cirrus formation in pristine environments (e.g. Heymsfield and Sabin, 1989; Cantrell and Heymsfield, 2005).

Heterogeneous freezing encompasses a group of nucleation "modes" (deposition, contact, immersion, and condensation) in which ice formation is mediated by insoluble solids (Pruppacher and Klett, 1997) or surfactant layers (Zobrist et al., 2007) that lower the energy barrier for the formation of an ice germ. Macroscopically, this can be expressed as a decrease in the freezing saturation threshold (or an increase in the freezing temperature) with respect the value

Published by Copernicus Publications on behalf of the European Geosciences Union. 
for homogeneous freezing. Aerosol particles that contribute such surfaces and undergo heterogeneous freezing are termed ice nuclei (IN) (Pruppacher and Klett, 1997); the nature of IN is very diverse and not well understood. They can be composed of mineral dust (DeMott et al., 2003b; Sassen et al., 2003), sulfates (Abbatt et al., 2006), crustal material (Zuberi et al., 2002; Hung et al., 2003), carbonaceous material (Beaver et al., 2006; Cozic et al., 2006; Zobrist et al., 2006), metallic particles (Al, Fe, Ti, Cr, Zn, and $\mathrm{Ca}$ ) (Chen et al., 1998; DeMott et al., 2003a), and biological particles (e.g. Möhler et al., 2007). Sources of IN have been associated with long range transport of dust (DeMott et al., 2003b; Sassen et al., 2003), pollution (Fridlind et al., 2004), and direct aircraft emissions (Penner et al., 1999; Minnis, 2004). Heterogeneous freezing saturation thresholds, $S_{h}$, depend primarily on the IN size, composition, and molecular structure, as well as on particle history (Cziczo and Abbatt, 2001; Möhler et al., 2005; Abbatt et al., 2006). Experimental studies have shown $S_{h}$ ranging from 1.1 to 1.5 (e.g. Heymsfield et al., 1998; DeMott et al., 2003a; Haag et al., 2003; Archuleta et al., 2005; Field et al., 2006; Prenni et al., 2007).

Field campaign data generally show that ice crystals collected at conditions favorable for homogeneous freezing contain a moderate fraction of insoluble material (e.g. DeMott et al., 2003a; Prenni et al., 2007), which suggests the potential for interaction between homogeneous and heterogeneous freezing during cirrus formation. Therefore, a comprehensive understanding of ice formation requires a combined theory of homogeneous and heterogeneous freezing (e.g. Vali, 1994; Kärcher and Lohmann, 2003; Khvorostyanov and Curry, 2004; Zobrist et al., 2008). Modeling studies however suggest (Kärcher and Lohmann, 2003; Khvorostyanov and Curry, 2005; Liu and Penner, 2005; Monier et al., 2006) that at atmospherically relevant conditions, a single mechanism (i.e. homogeneous or heterogeneous) dominates the freezing process. This is largely because IN tend to freeze first, depleting water vapor, and inhibiting homogenous nucleation before it occurs (DeMott et al., 1997); only if IN concentration is low enough can homogeneous freezing occur. Thus, IN and supercooled droplets may be considered separate populations that interact through the gas phase, but undergo heterogeneous or homogeneous freezing, respectively, at different stages during cloud formation (DeMott et al., 1997). This distinction may become less clear for heterogeneous freezing in the immersion mode for low concentration of immersed solid, or, if the solid is not an efficient ice nuclei (i.e. $S_{h}$ is high, close to the value for homogeneous freezing) (Khvorostyanov and Curry, 2004; Marcolli et al., 2007); we will assume for the rest of this study that we are far from such conditions, given that their importance for the atmosphere is not clear.

The presence of IN may drastically reduce the crystal concentration compared to levels expected for homogeneous freezing (DeMott et al., 1994, 1998), creating a potential anthropogenic indirect effect of IN on climate (DeMott et al., 1997; Kärcher and Lohmann, 2003). Therefore, parameterizations of cirrus formation for use in climate models should explicitly resolve the interaction between homogeneous and heterogeneous freezing. Using a simplified approach to describe the growth of ice particles and box model simulations, Gierens (2003) obtained a semi-analytical expression to estimate the limiting IN number concentration that would prevent homogeneous nucleation. Later, Ren and Mackenzi (2005) derived analytical constraints for the effect of monodisperse IN on homogeneous freezing; these analytical constraints are not generally applicable to all cloud formation conditions. Liu and Penner (2005) used parcel model simulations for combined homogeneous and heterogeneous freezing cases to obtain numerical fits relating $N_{c}$ to $T, V$, and $N_{\mathrm{IN}}$. Although based on simulations, such parameterizations are limited to the choice of IN type, concentration, freezing thresholds and assumptions on crystal growth (i.e. deposition coefficient) made during their derivation. The first comprehensive physically-based parameterization of cirrus formation was presented by Kärcher et al. (2006) in which homogeneous and heterogeneous nucleation are considered. In this scheme, the competition between different freezing mechanisms and particle types is resolved by using numerical integration to calculate the size and number of ice crystals at different stages of the parcel ascent. Although accurate, this method may be computationally expensive and does not analytically unravel the dependence of $N_{c}$ on key IN properties, like $S_{h}$ and $N_{\mathrm{IN}}$.

This study presents an analytical parameterization of cirrus formation that addresses the issues identified above and explicitly considers the competition between homogeneous and heterogeneous nucleation. We develop a novel method to account for the growth of the heterogeneously frozen ice crystals and incorporate their effect within the physicallybased homogeneous nucleation framework of Barahona and Nenes (2008, hereinafter BN08). The new parameterization explicitly resolves the dependency of $N_{c}$ on dynamical conditions of cloud formation (i.e. temperature, pressure, and updraft velocity), aerosol number, size, the characteristics of IN and their effect on ice saturation ratio. To clearly present the approach used to unravel the interactions between IN and supercooled droplets, we assume IN are monodisperse and chemically uniform. The extension of the parameterization to polydisperse IN (in size and chemical composition) will be presented in a companion study.

\section{Parameterization development}

The parameterization is based on the ascending parcel conceptual framework. Contained within the cooling parcel is a population of supercooled droplets externally mixed with IN that compete for water vapor when their characteristic freezing threshold is met. Heterogeneous and homogeneous freezing occur sequentially as the parcel water vapor saturation 
ratio over ice, $S_{i}$, increases during the cloud formation process. Homogeneous freezing is restricted to liquid droplets and described using the formulation of BN08. The IN population can be characterized by its number concentration, $N_{\mathrm{IN}}$, and freezing threshold, $S_{h}$. Upon freezing, ice grows on the IN, depleting and redistributing the available water vapor between the homogeneously and heterogeneously frozen crystals (i.e. IN-frozen crystals) (e.g. Lin et al., 2002; Ren and Mackenzie, 2005; Kärcher et al., 2006). Water vapor competition also affects the size distribution of homogeneously frozen crystals. To account for this competition effect, the change in homogeneous freezing probability due to the presence of IN-frozen crystals (i.e. the amount of water vapor condensed upon IN), and the size of the IN-frozen crystals at the homogenous freezing threshold, should be calculated. Both effects can be directly related to the impact of IN-frozen crystals on the rate of change of $S_{i}$ (Barahona and Nenes, 2008). A method to represent such interactions is presented below.

According to the homogeneous nucleation framework of $\mathrm{BN} 08$, the fraction of frozen droplets for a pure homogeneous pulse is given by

$f_{c}=\frac{\rho_{a}}{\rho_{i}} \frac{[k(T)]^{1 / 2}}{\beta N_{o}}\left[\frac{2 \alpha V S_{\max }}{\pi \bar{\Gamma}\left(S_{\max }-1\right)}\right]^{3 / 2}$

where symbols are defined in Appendix A and B. Equation (1) was obtained under the assumption that homogeneously nucleated ice crystals do not substantially impact $S_{i}$, up to the point of maximum ice saturation ratio (in reality, $S_{i}$ is affected, and is accounted for by adjusting the effective growth parameter $\bar{\Gamma}$ and setting $S_{\max }$ equal to the homogenous nucleation threshold).

The $\alpha V S_{\max }$ term in Eq. (1) represents the rate of change of $S_{i}$ at $S_{\max }$. The presence of IN perturbs $S_{\max }$, but Eq. (1) can still be applied if $\alpha V S_{\max }$ is replaced with the (perturbed) rate of change of $S_{i}, \dot{S}_{\max , \text { IN }}$ (calculated in Sect. 2),

$f_{c, \mathrm{IN}}=\frac{\rho_{a}}{\rho_{i}} \frac{[k(T)]^{1 / 2}}{\beta N_{o}}\left[\frac{2 \dot{S}_{\mathrm{max}, \mathrm{IN}}}{\pi \bar{\Gamma}\left(S_{\max }-1\right)}\right]^{3 / 2}$

where $f_{c \text {.IN }}$ is the fraction of droplets frozen from homogeneous freezing in presence of IN (Eq. 2 can be formally derived using the procedure presented in BN08). The use of Eq. (2) implies that $\dot{S}_{\max , I N}$ is almost constant during the homogeneous freezing pulse, even when IN are present. This is because, by the time homogeneous freezing occurs, the IN have reached large sizes (and grow very slowly); since the condensation rate is proportional to the available surface area (which can be considered constant over the timescale of $S_{\max }$, which is around $10^{-3} \mathrm{~V}$ s, with $V$ in $\mathrm{m} \mathrm{s}^{-1}$ ), $\dot{S}_{\text {max }, \text { IN }} \approx$ const.

Dividing Eqs. (1) and (2) by parts we obtain,

$\frac{f_{c, \mathrm{IN}}}{f_{c}}=\left[\frac{\dot{S}_{\mathrm{max}, \mathrm{IN}}}{\alpha \mathrm{VS} \max }\right]^{3 / 2}$ as all other terms in Eqs. (1) and (2) depend mainly on $T$ (Appendix A). Equation (3) expresses the impact of IN on the fraction of frozen droplets, which results from the redistribution of water vapor to IN-frozen crystals, and, the increase in the average size of the homogeneously frozen crystals due to a longer freezing pulse, which for the pure homogeneous case (in s) is approximately $\frac{25}{V}$ (with $V$ in $\mathrm{m} \mathrm{s}^{-1}$ ) (Barahona and Nenes, 2008). Both of these effects tend to decrease $f_{c \text {,IN }}$ relative to $f_{c}$. When no IN are present, the freezing pulse is purely homogeneous and $f_{c, \text { IN }}=f_{c}$. If $f_{c, \text { IN }}$ is known, the number of crystals in the cirrus cloud, $N_{c}$, can be calculated as

$N_{c}=N_{o} e^{-f_{c, \mathrm{IN}}}\left(1-e^{-f_{c, \mathrm{IN}}}\right)+N_{\mathrm{IN}}$

where $N_{o}$ is the liquid droplet number concentration in the parcel prior to freezing. The first term in Eq. (4) is the contribution from homogeneously frozen droplets (Barahona and Nenes, 2008), while the second term is from heterogeneous freezing.

2.1 Calculation of the size of the heterogeneously frozen crystals at $S_{\max }$

$\dot{S}_{\text {max,IN }}$ is required to find $f_{c, \text { IN }}$, and can be determined by solving a system of coupled ODEs that express the growth of heterogeneously frozen ice crystals and their impact on the parcel ice saturation ratio,

$\frac{d S_{i}}{d t}=\dot{S}_{i}=\alpha V S_{i}-\beta \frac{d w_{\mathrm{IN}}}{d t}$

$\frac{d w_{\mathrm{IN}}}{d t}=\frac{\rho_{i}}{\rho_{a}} \frac{\pi}{2} N_{\mathrm{IN}} D_{c, \mathrm{IN}}^{2} \frac{d D_{c, \mathrm{IN}}}{d t}$

$\frac{d D_{c, \mathrm{IN}}}{d t}=\frac{\left(S_{i}-1\right)}{\Gamma_{1} D_{c, \mathrm{IN}}+\Gamma_{2}}$

where symbols are defined in Appendix B. Equation (5) expresses the rate of change of parcel ice saturation ratio, which increases from cooling (first term of right hand side), and decreases from deposition on the growing IN (second term of right hand side). Equation (6) represents the rate of water vapor deposition on IN-frozen crystals. Equation (7) expresses the rate of change of crystal size due to water vapor condensation.

Equation (5), evaluated at $S_{\max }$ provides $\dot{S}_{\text {max,IN }}$. If the initial conditions of the parcel are known, Eqs. (5) to (7) can be numerically solved, as closed solution of Eqs. (5) to (7) is challenging. If $N_{\mathrm{IN}}$ and $S_{h}$ are such that $\left.\frac{d S_{i}}{d t}\right|_{S_{\max }}=0$, then Eqs. (5) to (7) become very stiff as $S_{i} \rightarrow S_{\max }$, so even numerical integration of the system becomes difficult.

Although a general closed solution to Eqs. (5) to (7) is not possible, an approximation can be derived. Based on numerical simulations of Eqs. (5) to (7), and examining the impact of IN on $S_{i}, \frac{d S_{i}}{d t}$, and $\dot{S}_{\max , I N}$, the behavior outlined in Fig. 1 


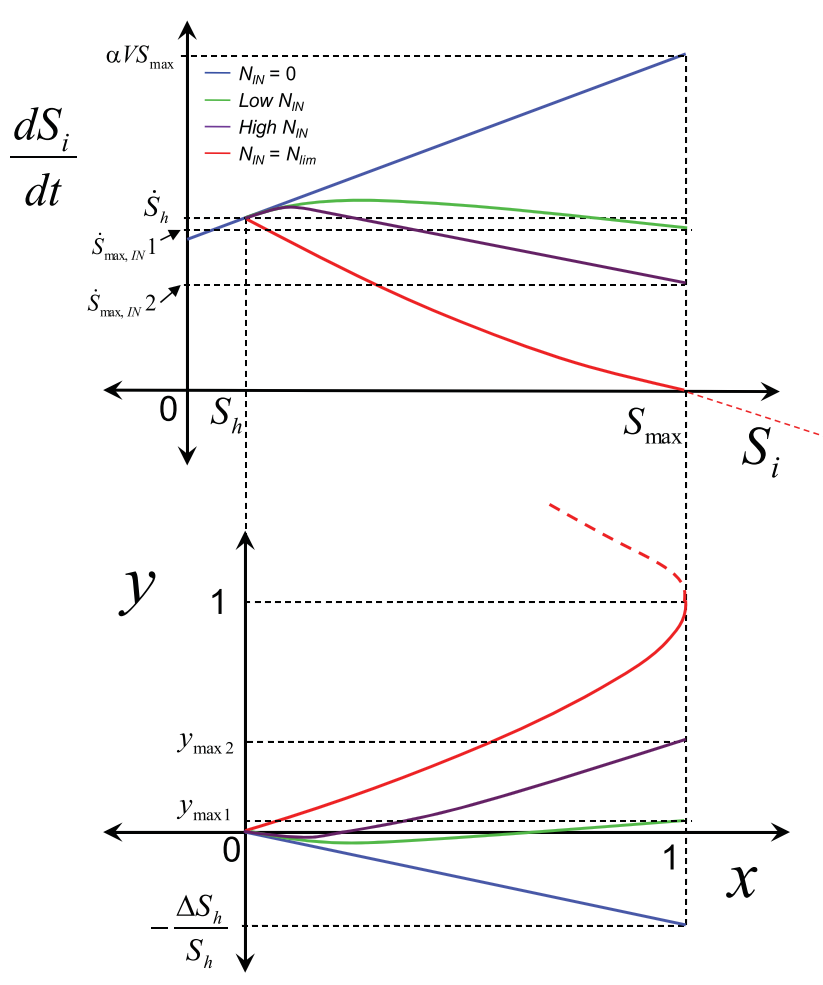

Fig. 1. Schematic relation between $x, y, S_{i}$, and $\frac{d S_{i}}{d t}$.

(top panel) is observed: (1) If $N_{\mathrm{IN}}=0$ (blue line), then $\frac{d S_{i}}{d t}$ vs. $S_{i}$ is linear and $\dot{S}_{\max , \mathrm{IN}}=\alpha V S_{\max }$ (Eq. 5). (2) If $N_{\mathrm{IN}}$ is low (green curve), IN-frozen crystals affect $\frac{d S_{i}}{d t}$ only after they grow substantially large; the resulting $\dot{S}_{\max , I N}$ is slightly below its value at $S_{h}, \dot{S}_{h}=\alpha V S_{h}$, (shown as $\left.\dot{S}_{\max , I N} 1\right)$. (3) A similar behavior is obtained for higher $N_{\text {IN }}$ (purple curve), however IN impact $\frac{d S_{i}}{d t}$ more quickly, and a lower $\dot{S}_{\max , \text { IN }}$ is reached (point $\dot{S}_{\max , \text { IN }} 2$ ). (4) If $N_{\text {IN }}$ is large enough, then the deposition rate on the ice crystals equals the rate of cooling from expansion, so that $\left.\frac{d S_{i}}{d t}\right|_{S_{\max }}=0$, i.e. $\dot{S}_{\max , \mathrm{IN}}=0$ (red curve) and corresponds to the inhibition of homogeneous nucleation due to IN freezing (Gierens, 2003; Ren and Mackenzie, 2005).

The behavior outlined above can be described in terms of the following dimensionless variables,

$x=\frac{S_{i}-S_{h}}{\Delta S_{h}}$

where $\Delta S_{h}=S_{\max }-S_{h}$, and

$y=\frac{\dot{S}_{h}-\frac{d S_{i}}{d t}}{\dot{S}_{h}}$

where, $\dot{S}_{h}=\alpha V S_{h}$, is the rate of change of $S_{i}$ at the instant when IN freeze. $x$ represents a normalization of $S_{i}$ by the difference between homogeneous and heterogeneous freezing thresholds, and $y$ represents a normalized $\frac{d S_{i}}{d t}$ with respect to its value at $S_{h}$. The relation between $x, y, S_{i}$, and $\frac{d S_{i}}{d t}$ is presented in Fig. 1. If $N_{\mathrm{IN}}=0$ (blue line), $x$ vs. $y$ is linear and the value of $y$ at $x=1$ (termed " $y_{\max }$ ") is equal to $-\frac{\Delta S_{h}}{S_{h}}$ (Eq. 9). Increasing $N_{\mathrm{IN}}$ is reflected by increase in $y_{\max }$ ( $y_{\max 1}$ and $y_{\max 2}$, for green and purple curves, respectively), in these cases the change in the sign of $y$ (Fig. 1, bottom panel) is related to the onset of significant depletion of water vapor, which impacts $\frac{d S_{i}}{d t} . \dot{S}_{\max , I N}=0$ is represented as $y_{\max }=1$ (red curves); at this point $S_{i}$ passes by a maximum at $S_{\max }$ so that there are at least two values of $y$ for each value of $x$, one in the increasing branch of $S_{i}$ and the second as $S_{i}$ decreases (dashed red curves). Thus, at $x=y=1$ the functional dependency between $x$ and $y$ ceases to be univocal and $\lim _{y \rightarrow 1} \frac{d y}{d x}=\infty$, or, $\lim _{y \rightarrow 1} \frac{d x}{d y}=0$. At this limit, IN impact $\frac{d S_{i}}{d t}$ very quickly after freezing, and $y$ changes sign at very low $x$.

Based on the above analysis an approximate mathematical relation can be obtained between $x$ and $y$. Since $x$ is less than 1, together with $\left.\frac{d x}{d y}\right|_{y=1}=0$, a Taylor series expansion around $y=1$ gives,

$$
\left.\frac{d^{2} x}{d y^{2}}\right|_{y=1}=-K+O\left(y, y^{2}, \ldots\right)
$$

where $K$ is a positive constant, and $O\left(y, y^{2}, \ldots\right)$ are higher order terms that are neglected (the consequences of this assumption are discussed in Sect. 3). Since to zeroth order, the curvature around the point $y=1$ is constant (equal to $-K$ ), $x$ is related to $y$ as, $x=-K y^{2}+a y+b$ (being $a$ and $b$ integration constants). Since $x=0$ when $y=0$, and, $\frac{d x}{d y}=0$, for $y=1$, then $b=0, K=\frac{a}{2}$, and

$A x=y(y-2)$

where $A=-\frac{1}{a}$ is an arbitrary constant. As we desire $x$ and $y$ to be normalized, we select $A$ such that $x=1$ when $y=y_{\max }$, (Fig. 1), or $A=y_{\max }\left(y_{\max }-2\right)$. Substitution into Eq. (11) and rearranging gives

$y=1-\sqrt{1+A x}$

Equation (12) represents an approximation of $\frac{d S_{i}}{d t}$ vs. $S_{i}$ written in normalized form, and expresses the dependency between $\frac{d S_{i}}{d t}$ and $S_{i}$ considering cooling from expansion, and condensation of water vapor on ice crystals.

To find $\dot{S}_{\text {max,IN }}$, the rate of water vapor condensation on IN-frozen crystals at $S_{\max },\left.\frac{d w_{\mathrm{IN}}}{d t}\right|_{S_{\max }}$, must be calculated (Eq. 5); however, due to the coupling between Eqs. (6) and (7), this requires the calculation of the size of the IN-frozen crystals at $S_{\max }, D_{\max , I N}$. Equation (12) combined with Eq. (7) can be used for the latter, as follows. First, rearranging Eq. (7) and integrating from $S_{h}$ to $S_{\max }$ we obtain

$$
\frac{\Gamma_{1}}{2} D_{\max , \mathrm{IN}}^{2}+\Gamma_{2} D_{\max , \mathrm{IN}}-\Gamma\left(D_{o, \mathrm{IN}}\right)=\int_{t\left(S_{h}\right)}^{t\left(S_{\max }\right)}\left(S_{i}-1\right) d t
$$


where $\Gamma\left(D_{o, \mathrm{IN}}\right)=\frac{\Gamma_{1}}{2} D_{o, \mathrm{IN}}^{2}+\Gamma_{2} D_{o, \mathrm{IN}}$, and $D_{o, \mathrm{IN}}$ is the initial size of the IN at the point of freezing. In most cases, $\Gamma\left(D_{o, \mathrm{IN}}\right)$ in Eq. (13) can be neglected, since generally $D_{\max , \text { IN }} \gg D_{o, \text { IN }}$. From Eqs. (8) and (9), and using Eq. (12)

$S_{i}=x \Delta S_{h}+S_{h}$

and

$\frac{d S_{i}}{d t}=\Delta S_{h} \frac{d x}{d t}=\dot{S}_{h}(1-y)=\dot{S}_{h} \sqrt{1+A x}$

substituting Eq. (14a) and (14b) into Eq. (13), gives

$$
\begin{aligned}
& \int_{t\left(S_{h}\right)}^{t\left(S_{\max }\right)}\left(S_{i}-1\right) d t=\frac{\Delta S_{h}^{2}}{\dot{S}_{h}} \int_{0}^{1} \frac{x}{\sqrt{1+A x}} d x \\
& +\frac{\Delta S_{h}\left(S_{h}-1\right)}{\dot{S}_{h}} \int_{0}^{1} \frac{1}{\sqrt{1+A x}} d x
\end{aligned}
$$

integrating Eq. (15a), after substituting $A=y_{\max }\left(y_{\max }-2\right)$ and rearranging, gives

$$
\begin{aligned}
& \frac{\Delta S_{h}^{*}}{\dot{S}_{h}}=\int_{t\left(S_{h}\right)}^{t\left(S_{\max }\right)}\left(S_{i}-1\right) d t=\frac{1}{\dot{S}_{h}} \frac{2 \Delta S_{h}}{\left(2-y_{\max }\right)} \\
& {\left[\frac{\Delta S_{h}\left(3-y_{\max }\right)}{3\left(2-y_{\max }\right)}+\left(S_{h}-1\right)\right]}
\end{aligned}
$$

substituting Eq. (15b) into Eq. (13), and solving for $D_{\max , \text { IN }}$ gives,

$D_{\max , \mathrm{IN}}=-\frac{\Gamma_{2}}{\Gamma_{1}}+\sqrt{\left(\frac{\Gamma_{2}}{\Gamma_{1}}\right)^{2}+\frac{2}{\Gamma_{1}}\left[\frac{\Delta S_{h}^{*}}{\alpha V S_{h}}+\Gamma\left(D_{o, \mathrm{IN}}\right)\right]}$

where we have used $\dot{S}_{h}=\alpha V S_{h}$. Equation (16) uniquely defines $D_{\max , \text { IN }}$, and represents an approximated solution of the ODE system Eqs. (5) to (7), at the point of maximum ice saturation ratio in the parcel; $y_{\max }$ can be computed after combining Eqs. (6) and (7) and using Eq. (14b),

$$
\begin{aligned}
& \left.\frac{d S_{i}}{d t}\right|_{S_{\max }}=\alpha V S_{h}\left(1-y_{\max }\right) \\
& =\alpha V S_{\max }-\beta \frac{\rho_{i}}{\rho_{a}} \frac{\pi}{2} N_{\mathrm{IN}} D_{\max , \mathrm{IN}}^{2} \frac{\left(S_{\max }-1\right)}{\Gamma_{1} D_{\max , \mathrm{IN}}+\Gamma_{2}}
\end{aligned}
$$

\subsection{Limiting $N_{\text {IN }}$}

Besides defining a maximum in $S_{i}$, the condition $\left.\frac{d S_{i}}{d t}\right|_{S_{\max }}=0$, (red curves, Fig. 1) also defines the maximum condensation rate that can be achieved right before homogeneous freezing is prevented; any increase in $\frac{d w_{\text {IN }}}{d t}$ beyond this value implies pure heterogeneous freezing (Gierens, 2003). Figure 1 shows that this condition is uniquely determined by $y_{\max }=1$; the limiting size of the ice crystals, $D_{\text {lim }}$, at the maximum water vapor deposition rate can then be computed from Eq. (16) for $\Delta S_{h}^{*}$ calculated for $y_{\max }=1$,

$D_{\lim }=-\frac{\Gamma_{2}}{\Gamma_{1}}+\sqrt{\left(\frac{\Gamma_{2}}{\Gamma_{1}}\right)^{2}+\frac{2}{\Gamma_{1} \alpha V S_{h}}\left(\frac{4}{3} \Delta S_{h}^{2}+2 \Delta S_{h}\left(S_{h}-1\right)\right)}$

where $\Gamma\left(D_{o, \text { IN }}\right)$ has been neglected because $D_{\text {lim }} \gg D_{o, \text { IN }}$.

Equation (18) can be used to compute the limiting number concentration of IN that will prevent homogeneous nucleation, $N_{\text {lim }}$, as follows. Since $\left.\frac{d S_{i}}{d t}\right|_{S_{\max }}=0$, Eqs. (5) and (6) can be combined to give

$\beta \frac{\rho_{i}}{\rho_{a}} \frac{\pi}{2} N_{\lim } D_{\lim }^{2} \frac{d D_{\lim }}{d t}=\alpha V S_{\max }$

after substitution of Eqs. (18) and (7) into Eq. (19), $N_{\text {lim }}$ can be obtained as

$N_{\lim }=\frac{\alpha V}{\beta} \frac{\rho_{a}}{\rho_{i}} \frac{2}{\pi}\left(\frac{S_{\max }}{S_{\max }-1}\right)\left(\frac{\Gamma_{1} D_{\lim }+\Gamma_{2}}{D_{\lim }^{2}}\right)$

\subsection{Calculation of $f_{c, \mathrm{IN}}$}

The set of Eqs. (15) to (17) represents a closed system that can be used to find $\dot{S}_{\max , \text { IN }}$ (hence $f_{c, \text { IN }}$ ). Although the dependence of $D_{\max , \text { IN }}$ on $y_{\max }$ suggests an iterative procedure for calculation of $\dot{S}_{\max , I N}$, a faster alternative (developed below) can be used. Assuming that $D_{\text {max,IN }}$ is large enough so non-continuum effects can be neglected (i.e. $\Gamma_{1} D_{\max , I N} \gg \Gamma_{2}$ ), Eq. (6), after substituting Eq. (7) and setting $S_{i}=S_{\max }$, becomes

$$
\left.\frac{d w_{\mathrm{IN}}}{d t}\right|_{S_{\max }}=\frac{\rho_{i}}{\rho_{a}} \frac{\pi}{2} \frac{\left(S_{\max }-1\right)}{\Gamma_{1}} N_{\mathrm{IN}} D_{\max , \mathrm{IN}}
$$

rearranging Eq. (20), and assuming $\Gamma_{1} D_{\lim } \gg \Gamma_{2}$, gives

$$
\frac{S_{\max }-1}{\Gamma_{1}}=\left(\frac{\beta}{\alpha V S_{\max }} \frac{\pi}{2} \frac{\rho_{i}}{\rho_{a}} N_{\lim } D_{\lim }\right)^{-1}
$$

after substituting Eq. (22) into Eq. (21) we obtain

$$
\left.\frac{d w_{\mathrm{IN}}}{d t}\right|_{S_{\max }}=\frac{\alpha V S_{\max }}{\beta}\left(\frac{N_{\mathrm{IN}}}{N_{\lim }} \frac{D_{\mathrm{max}, \mathrm{IN}}}{D_{\lim }}\right)
$$

which after substituting into Eq. (7), at $S_{\max }$, gives

$$
\frac{\dot{S}_{\mathrm{max}, \mathrm{IN}}}{\alpha V S_{\max }}=1-\left(\frac{N_{\mathrm{IN}}}{N_{\mathrm{lim}}} \frac{D_{\max , \mathrm{IN}}}{D_{\mathrm{lim}}}\right)
$$

Equation (24) can be used to determine $\dot{S}_{\text {max,IN }}$, if a relation is found between $D_{\max , \text { IN }}$ and $D_{\text {lim }}$. Considering that at $N_{\text {IN }}=N_{\text {lim }}$ (hence $D_{\max , \text { IN }}=D_{\text {lim }}$ ) the surface area of the crystal population is the largest (which follows from Eq. (16) since for all $N_{\mathrm{IN}}<N_{\mathrm{lim}}, y_{\max }<1$ ) then the total surface area of the crystal population at $N_{\mathrm{IN}}$ can be related to its value at $N_{\text {lim }}$ by, 


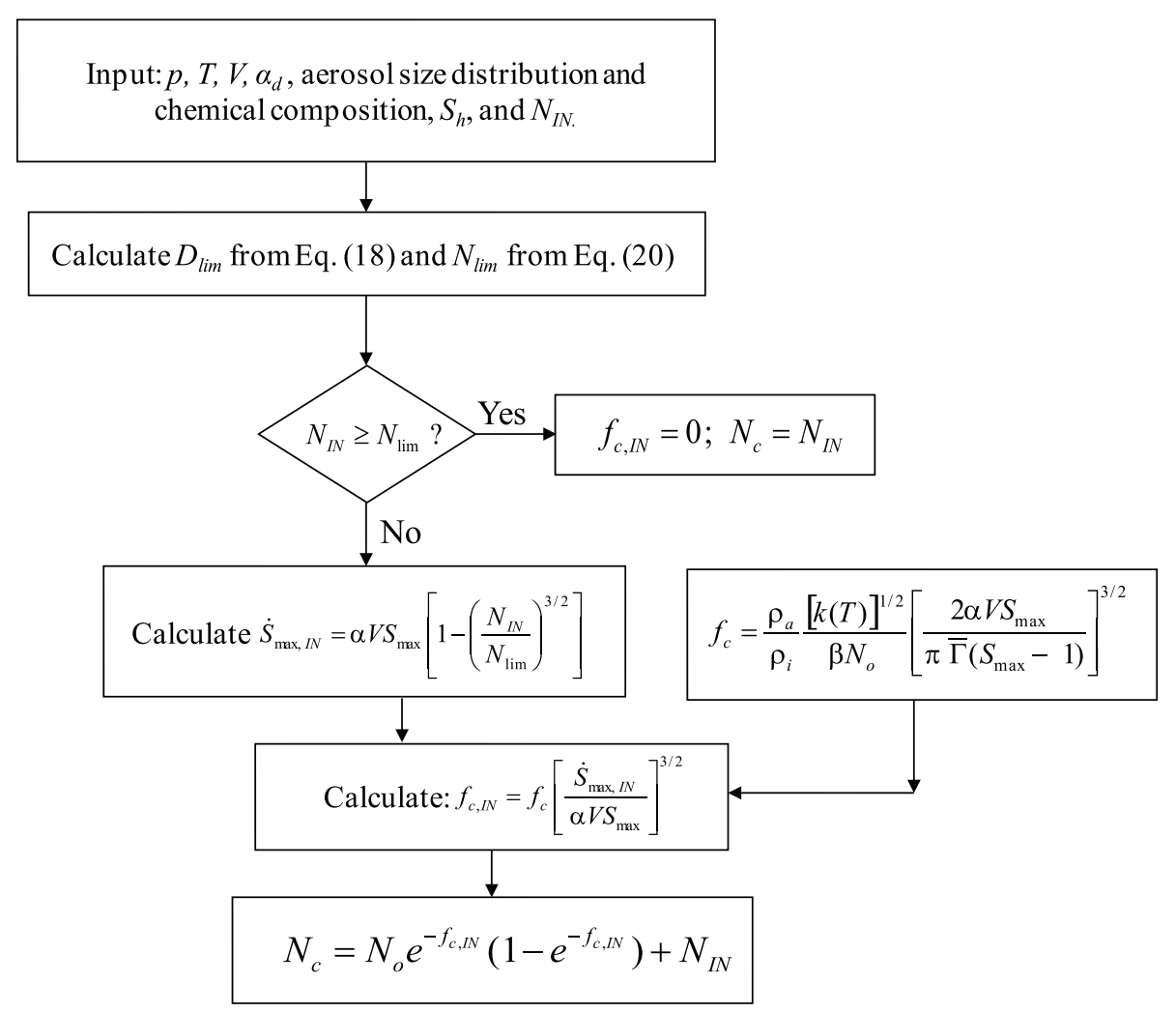

Fig. 2. Parameterization algorithm.

$N_{\mathrm{IN}} D_{\text {max }, \mathrm{IN}}^{2}+\left(N_{\mathrm{lim}}-N_{\mathrm{IN}}\right)\left(D_{\mathrm{lim}}-D_{\mathrm{max}, \mathrm{IN}}\right)^{2}=N_{\mathrm{lim}} D_{\mathrm{lim}}^{2}$

which after expanding the quadratic terms and rearranging, gives,

$\frac{N_{\mathrm{IN}}}{N_{\mathrm{lim}}}=\frac{D_{\mathrm{max}, \mathrm{IN}}^{2}-2 D_{\mathrm{lim}} D_{\mathrm{max}, \mathrm{IN}}}{D_{\mathrm{lim}}^{2}-2 D_{\lim } D_{\mathrm{max}, \mathrm{IN}}}$

typically, by the time $S_{i}$ reaches $S_{\max }$, ice crystals have grown to sizes comparable to $D_{\text {lim }}$, i.e. $D_{\text {max,IN }} \sim D_{\text {lim }}$, and Eq. (26) can be approximated as,

$\frac{N_{\mathrm{IN}}}{N_{\mathrm{lim}}} \approx \frac{D_{\mathrm{max}, \mathrm{IN}}^{2}}{D_{\mathrm{lim}}^{2}}$

Equation (27), when introduced into Eq. (24) gives,

$\frac{\dot{S}_{\mathrm{max}, \mathrm{IN}}}{\alpha V S_{\max }}=1-\left(\frac{N_{\mathrm{IN}}}{N_{\mathrm{lim}}}\left(\frac{N_{\mathrm{IN}}}{N_{\mathrm{lim}}}\right)^{1 / 2}\right)$

which can be solved for $\dot{S}_{\mathrm{max}, \mathrm{IN}}$ as,

$\dot{S}_{\text {max }, I N}=\alpha V S_{\max }\left[1-\left(\frac{N_{\mathrm{IN}}}{N_{\mathrm{lim}}}\right)^{3 / 2}\right]$

$\dot{S}_{\text {max,IN }}$ calculated from Eq. (29) can then be used into Eq. (3) to find $f_{c, \mathrm{IN}}$. The restriction that $\dot{S}_{\text {max,IN }}>0$ for all cases when homogeneous freezing is not prevented (e.g. Fig. 1) implies that $f_{c, \mathrm{IN}}=0$, if $N_{\mathrm{IN}} \geq N_{\text {lim. }}$.

\subsection{Applying the parameterization}

The application of the parameterization is outlined in Fig. 2. First, $D_{\lim }$ is computed from Eq. (18) and used in Eq. (20) to calculate $N_{\text {lim }}$; if $N_{\mathrm{IN}} \geq N_{\text {lim }}$ then $f_{c, \text { IN }}=0$. If $N_{\text {IN }}<N_{\text {lim }}$, $\dot{S}_{\text {max,IN }}$ is then obtained from Eq. (29), which after substitution into Eq. (3) (using Eq. 1 to obtain $f_{c}$ ), gives $f_{c, \text { IN }}$. Equation (5) is used then to calculate $N_{c}$ from combined heterogeneous and homogeneous freezing.

\section{Results and discussion}

The parameterization was evaluated against the numerical parcel model developed in BN08, modified to include the effect of IN (by allowing the deposition of water vapor onto the IN when $S_{i}$ exceeds $S_{h}$ ). The performance of the parameterization for pure homogeneous freezing conditions was discussed in BN08, so the evaluation here is focused on the competition between homogeneous and heterogeneous freezing. The conditions used for evaluation covered a wide range of $T, V, \alpha_{d}, S_{h}$ and $N_{\text {IN }}$ (Table 1) for a total of 800 simulations; initial $p$ was estimated from hydrostatic equilibrium at $T_{o}$ using a dry adiabatic lapse rate. For simplicity, $\alpha_{d}$ was assumed to be the same for the homogeneously frozen and IN-frozen ice crystal populations (although this assumption can easily be relaxed). 

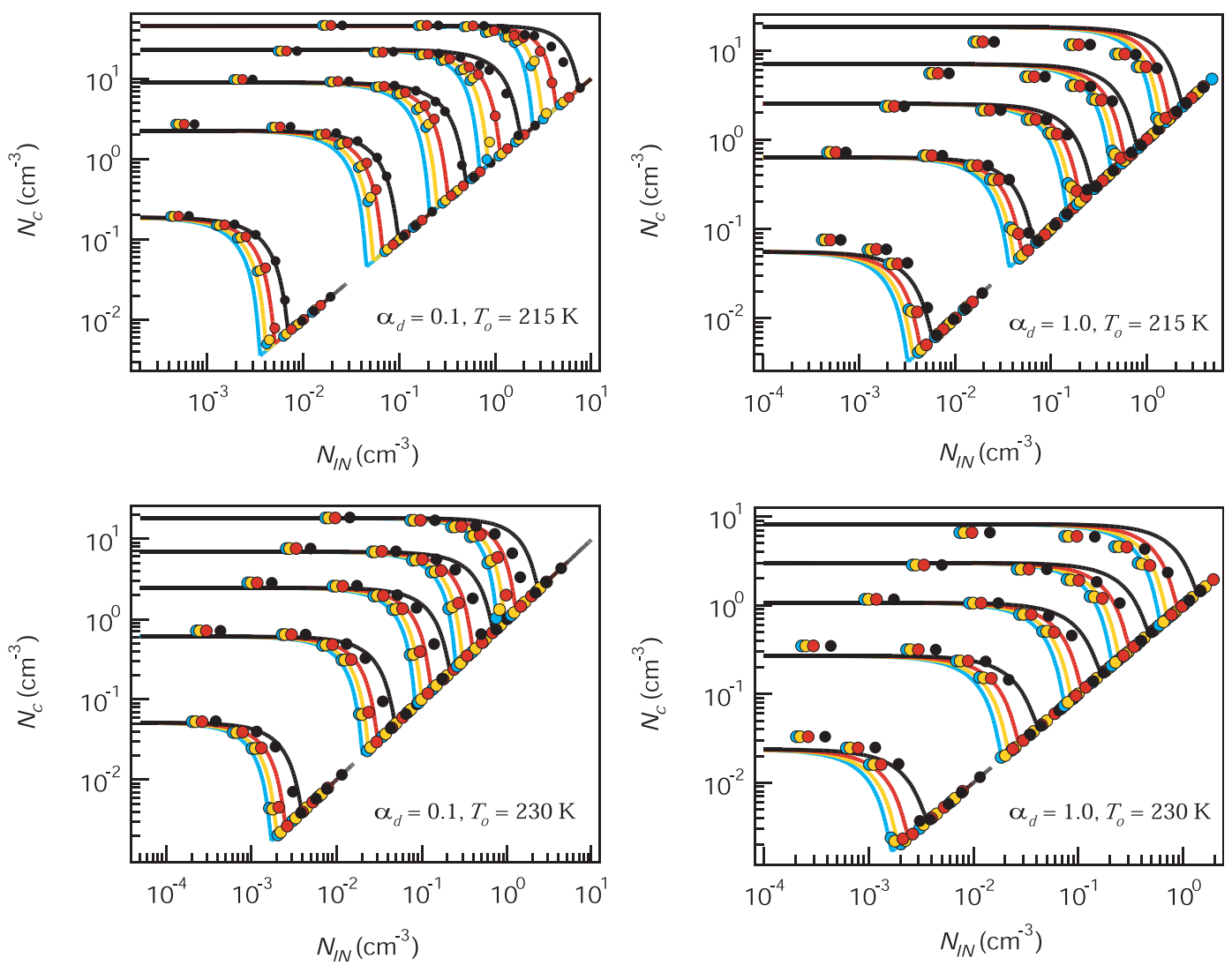

Fig. 3. $N_{c}$ vs. $N_{\text {IN }}$ for all simulation conditions of Table 1. Lines represent parameterization results and symbols correspond to parcel model simulations. Symbols are colored by $S_{h}$, being 1.1 (blue), 1.2 (yellow), 1.3 (red), and 1.4 (black). $V$ is equal to $0.04,0.2,0.5,1$, and $2 \mathrm{~m} \mathrm{~s}{ }^{-1}$, from bottom to top lines in each panel, respectively.

\subsection{Evaluation against parcel model}

Figure 3 presents $N_{c}$ versus $N_{\text {IN }}$ using the parameterization (lines) and the parcel model (symbols), for all the simulations of Table 1. At low $N_{\mathrm{IN}}\left(\sim\right.$ less than $\left.10^{-4} \mathrm{~cm}^{-3}\right)$, the impact of IN on $N_{c}$ is minimal and $N_{c}$ is close to the obtained under pure homogeneous freezing. As $N_{\mathrm{IN}}$ increases to about $0.1 N_{\text {lim }}$, IN considerably impact $N_{c}$, so that $N_{c}$ reduces proportionally to $N_{\text {IN }}$ up to the prevention of homogeneous nucleation at $N_{\mathrm{IN}}=N_{\mathrm{lim}}$, at which a minimum $N_{c}=N_{\text {lim }}$ is reached. When $N_{\text {IN }}$ is greater than $N_{\text {lim }}$, freezing is only heterogeneous and $N_{c}=N_{\mathrm{IN}}$. Figure 3 shows that at high $V$ and low $T$, large concentrations of IN $\left(N_{\mathrm{lim}} \sim 1 \mathrm{~cm}^{-3}\right)$ are required to impact homogeneous freezing, which is consistent with existing studies (e.g. DeMott et al., 1997); given that high $N_{\text {IN }}$ are rare in the upper troposphere (e.g. Gayet et al., 2004; Prenni et al., 2007), our results are consistent with current understanding that homogeneous nucleation is the primary freezing mechanism at these conditions.

Overall, the parameterization reproduces very well the parcel model results (Fig. 3), and clearly captures the effect of $N_{\text {IN }}$ on $N_{c}$. When calculating the error between parcel model and parameterization, care should be taken to exclude
Table 1. Cloud formation conditions used in evaluation.

\begin{tabular}{ll}
\hline Property & Values \\
\hline$T_{o}(\mathrm{~K})$ & 215,230 \\
$V\left(\mathrm{~m} \mathrm{~s}^{-1}\right)$ & $0.04-2$ \\
$\alpha_{d}$ & $0.1,1.0$ \\
$\sigma_{g, \text { dry }}$ & 2.3 \\
$N_{o}\left(\mathrm{~cm}^{-3}\right)$ & 200 \\
$D_{g, \text { dry }}(\mathrm{nm})$ & 40 \\
$S_{h}$ & $1.1-1.4$ \\
$N_{\text {IN }} / N_{\text {lim }}$ & $0.01-3$ \\
\hline
\end{tabular}

points where homogeneous nucleation is prevented, as both the parameterization and the parcel model predict $N_{c}=N_{\mathrm{IN}}$ (i.e. $f_{c, \text { IN }}=0$ Eq. 29). Including these points in the analysis would bias the error estimation towards low values. Omitting points where $N_{c}=N_{\text {IN }}$ (i.e. where homogeneous freezing does not occur), the average relative error for the calculation of $N_{c}$ using the parameterization with respect to parcel model results for all the runs of Table 1 , is about $6 \pm 33 \%$. The 


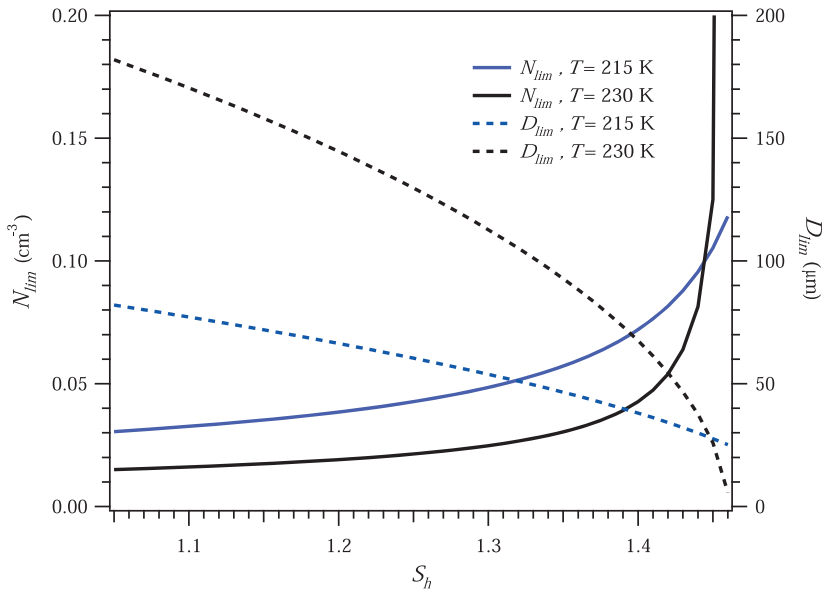

Fig. 4. $N_{\lim }$ vs. $S_{h}$ (solid line) and $D_{\text {lim }}$ vs. $S_{h}$ (dashed line) for $V=0.2 \mathrm{~m} \mathrm{~s}^{-1}, \alpha_{d}=0.1$.

small value of the error indicates no significant systematic biases in the parameterization over the broad range of conditions considered. Still, some overprediction is found at $N_{c}$ at $V=2 \mathrm{~m} \mathrm{~s}^{-1}$, and a slight underprediction at $V=0.04 \mathrm{~m} \mathrm{~s}^{-1}$ and $T=230 \mathrm{~K}$. The former bias is not critical as such high $V$ are typically not encountered during cirrus formation. The latter can be attributed to the inherent error of the homogeneous framework of BN08 $(1 \pm 28 \%)$, as a much better agreement is obtained if $f_{c}$ (homogeneous) is replaced with the numerical solution.

\subsection{Understanding sources of error}

Discrepancy between the parameterization and the parcel model originate from (i) assumptions made in obtaining Eq. (29), which determines the shape of the curves $N_{c}$ vs. $N_{\text {IN }}$, and, (ii) from errors in the calculation of $N_{\text {lim }}$, Eq. (20), which determines the minimum $N_{c}$. The relative contribution of each source of error can be assessed by calculating the average difference in $N_{c}$ between the parcel model and the parameterization, normalized by the corresponding $N_{c}$ (from parcel model results) obtained from pure homogeneous freezing (i.e. $N_{c}$ for $N_{\mathrm{IN}} \rightarrow 0$, Fig. 3); which is about $1 \pm 10 \%$ for all simulations of Table 1 . This suggests that most of the discrepancy between parameterization and parcel model results occurs at low $N_{c}\left(N_{\text {IN }}\right.$ close to $\left.N_{\text {lim }}\right)$, therefore, most of the error in the parameterization should result from the calculation of $N_{\text {lim }}$. This is supported by the simulations in Fig. 3, which show that the shape of the parameterized $N_{c}$ vs. $N_{\text {IN }}$ follows well the parcel model results, and discrepancy between the parameterization and parcel model mainly originates from slight "shifting" in $N_{\text {lim }}$.

Potential sources of error in the calculation of $N_{\text {lim }}$ can be identified by analyzing Eq. (20). First, $S_{\max }$ has been assumed to remain constant during the homogeneous pulse. Although this is a good approximation for computing $N_{c}$ from homogeneous nucleation, $\Delta S_{h}$, which is dependent on $S_{\max }$ (Eq. 18), may be in error and bias the calculation of $D_{\lim }$ (hence $N_{\text {lim }}$ ). This is shown in Fig. 4, which presents $D_{\text {lim }}$ (dotted lines) and $N_{\text {lim }}$ (solid lines) as a function of $S_{h}$, for $T=215 \mathrm{~K}\left(S_{\max }=1.51\right.$, blue lines $)$ and $T=230 \mathrm{~K}$ $\left(S_{\max }=1.46\right.$, black lines). At low $S_{h}\left(\Delta S_{h}>0.1\right), D_{\text {lim }}$ decreases almost linearly with $S_{h}$. For $\Delta S_{h}<0.1$, the dependency of $D_{\text {lim }}$ on $S_{h}$ changes so that $D_{\text {lim }} \rightarrow 0$ when $S_{h} \rightarrow S_{\max }$. As a result, for $\Delta S_{h}>0.1, N_{\text {lim }}$ is almost linear in $S_{h}$ (Eq. 22) and insensitive to small errors in $S_{\max }$. As $S_{h} \rightarrow S_{\text {max }}, N_{\text {lim }}$ increases steeply and becomes very sensitive to errors in $S_{\max }$. This is strongly evident for $T=230 \mathrm{~K}$ when $S_{h}>1.4$ (Fig. 4). At these conditions, $\Delta S_{h}<0.06$, the parameterization becomes very sensitive to the value of $S_{\max }$ (Fig. 3 for $S_{h}=1.4$ and $T=230 \mathrm{~K}$, i.e. black lines and circles), and tends to overestimate $N_{\text {lim }}$ because the parameterized $S_{\max }$ is below $S_{\max }$ reached in the parcel model simulations. This effect is more pronounced at high $V$ (Fig. 3) as $S_{\max }$ tend to reach high values at such conditions. The overestimation in $N_{\lim }$ at $S_{h}=1.4$, however, is less pronounced at $T=215 \mathrm{~K}$ (Fig. 3 upper panels); for these conditions $\Delta S_{h}>0.1$, so the parameterization is insensitive to the error in $S_{\max }$. It is also noticeable that at low $V\left(<0.2 \mathrm{~m} \mathrm{~s}^{-1}\right)$ the parameterized $S_{\max }$ does not introduce significant errors in $N_{\text {lim. }}$.

Another potential source of error in the parameterization lies in neglecting the higher order terms in Eq. (10), $O\left(y, y^{2}, \ldots\right)$. Because of this, Eq. (12), will not predict a change in the sign of $y$ (e.g. green line, Fig. 1), and cannot describe the time "lag" before appreciable condensation rates are achieved upon the IN and the impact of ice crystals on $\frac{d S_{i}}{d t}$ becomes significant. Since Eq. (12) predicts an instantaneous effect of IN on $\frac{d S_{i}}{d t}$ (e.g. red line Fig. 1), neglecting $O\left(y, y^{2}, \ldots\right)$ become less important when the impact of $N_{\text {IN }}$ on $\frac{d S_{i}}{d t}$ is the highest, i.e. $N_{\mathrm{IN}}=N_{\mathrm{lim}}$. Moreover, the error introduced by neglecting $O\left(y, y^{2}, \ldots\right)$ is in general not critical to calculate $f_{c, \text { IN }}$, since at low $N_{\text {IN }}$ the impact of IN on homogeneous nucleation is small.

Some bias may also be introduced when $S_{h}$ is low. At these conditions, recently frozen crystals are exposed to low $S_{h}$ therefore grow slowly, so even at $N_{\text {IN }}=N_{\text {lim }}$ there is a substantial time lag before they can impact ice saturation ratio. Since Eq. (12) does not account for this, $D_{\text {lim }}$ is slightly overpredicted and $N_{\mathrm{lim}}$ underpredicted (e.g. Fig. 3). This "growth lag" effect is even stronger at low $T$ and low $\alpha_{d}$ since condensation (growth) rates are further decreased. This is seen in the slight underprediction of the parameterization shown in Fig. 3 at $S_{h}=1.1$ and $T=215 \mathrm{~K}$ (upper panels, blue lines and circles).

\subsection{Evaluation against other parameterizations}

We first compare the new parameterization against the formulation of Kärcher et al. (2006, K06). K06 was developed for a polydisperse aerosol distribution, but it can be 
compared against the new parameterization provided that $S_{\max }>S_{h}$ (for such conditions, the polydisperse population with a single freezing threshold can be well approximated by a chemically uniform and monodisperse IN with freezing threshold $S_{h}$ ). Simulations are carried out for $T_{o}=210 \mathrm{~K}$, $230 \mathrm{~K}, p=22000 \mathrm{~Pa}$, and $\alpha_{d}=0.5 ; N_{\mathrm{IN}}$ was set to 1,5 , and $301^{-1}$, and, $S_{h}$ to 1.3. Results for K06 were obtained from Kärcher et al. (2006). Figure 5 shows the comparison between the two parameterizations; both formulations agree remarkably well. Slight discrepancies between the parameterization and $\mathrm{K} 06$ are found at $T_{o}=210 \mathrm{~K}$ and $N_{\mathrm{IN}}=1$ and $51^{-1}$, which is explained by the differences in the homogeneous scheme of BN08 and K06, as analyzed in Barahona and Nenes (2008). For very low $V\left(<0.03 \mathrm{~m} \mathrm{~s}^{-1}\right), S_{\max }<S_{h}$, and, comparison against K06 is not possible. Such conditions require a polydisperse formulation, and will be addressed in a companion study.

Finally, we compared Eq. (20) to the expressions provided for $N_{\text {lim }}$ by Gierens (2003, G03) and Liu and Penner (2005, LP05). LP05 (Fig. 6, green circles) is based on detailed parcel model simulations and resolves the dependency of $N_{\text {lim }}$ on $T$ and $V$. G03 (Fig. 6, stars) uses a semi-analytical approach, where box model simulations are employed to fit the time scale of growth of the ice crystals; it resolves explicitly the dependency of $N_{\lim }$ on $T, V, S_{h}$ and $p$. Figure 6 presents the results of the three expressions as functions of $T$ (left panel, $V=0.1 \mathrm{~m} \mathrm{~s}^{-1}$ ) and $V$ (right panel, $T=215 \mathrm{~K}$ ), and $S_{h}=1.3$ (blue) and 1.4 (black). Equation (20) is presented in Fig. 6 for $\alpha_{d}=0.1$ (dashed lines) and 1 (solid lines). At a given $V$ (Fig. 6, left panel), $N_{\text {lim }}$ decreases almost exponentially with increasing $T$. The difference between $N_{\text {lim }}$ predicted by G03 and Eq. (20) is the largest at $T=200 \mathrm{~K}$, but is minimal at $T=230 \mathrm{~K}$. The convergence at high $T$ is likely from the large crystal size attained, which implies that the mass transfer coefficient is consistent with the approximation taken in G03 of neglecting kinetic effects. LP05 predicts $N_{\text {lim }}$ about one order of magnitude lower than Eq. (20), potentially because they included both deposition and immersion freezing in their simulations; deposition IN would act as a second population (with different $S_{h}$ and $N_{\mathrm{IN}}$ ) that would compete for water vapor with the existing crystals lowering $N_{\text {lim }}$. Equation (20) cannot currently represent such a case, but can be expanded to include it and will be the subject of a future study. At fixed T, G03 and Eq. (20) predict a $N_{\text {lim }} \sim V^{3 / 2}$ dependency (Fig. 6, right panel). LP05 shows a higher order dependency, likely due to the effect of deposition IN depleting water vapor.

\section{Summary and conclusions}

We developed an analytical parameterization for cirrus formation that explicitly considers the competition between homogeneous and heterogeneous nucleation. Using functional analysis of the crystal growth and ice saturation ratio evolu-

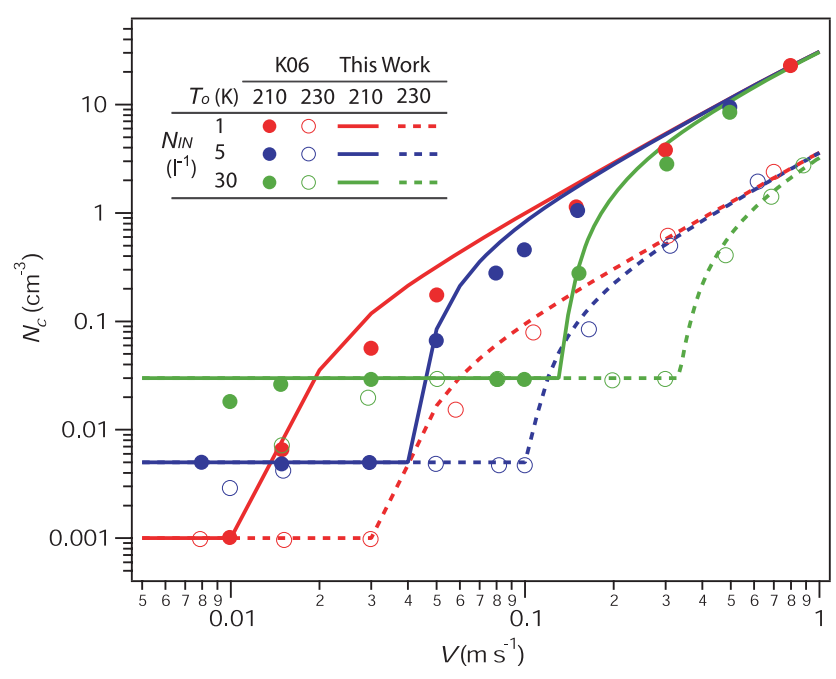

Fig. 5. Comparison of new parameterization (lines) against the formulation of Kärcher et al. (2006) (symbols). Simulations shown are for $T_{o}=210 \mathrm{~K}, 230 \mathrm{~K}, p=22000 \mathrm{~Pa}$, and, $\alpha_{d}=0.5$. $N_{\mathrm{IN}}$ was set to 1 , 5 , and $301^{-1}$, and, $S_{h}$ to 1.3 .

tion equations for a cloud parcel, an expression relating $\frac{d S_{i}}{d t}$ to $S_{i}$ was found, and used to calculate the limiting size of the ice crystals, $D_{\text {lim }}$, and limiting concentration of IN that would prevent homogeneous nucleation, $N_{\text {lim }}$. These two parameters were employed to obtain a simple, yet accurate, expression to account for the reduction in $\frac{d S_{i}}{d t}$ due to the presence of previously frozen crystals which, when incorporated within the physically-based homogeneous nucleation framework of Barahona and Nenes (2008), allows the calculation of the number of crystals produced when heterogeneous and homogeneous freezing mechanisms compete for water vapor during cirrus cloud formation.

Previous work, using numerical parcel simulations, determine "heterogeneously-dominated" and "homogeneouslydominated" regimes and correlate them with cloud formation conditions $(V, T$, and $P$ ). However, it was demonstrated that at conditions where homogeneous freezing typically dominates (i.e., high $V$ and low $T$ ), ice crystal formation can be affected by IN, provided that $N_{\mathrm{IN}}$ is high enough. Thus, $V$ and $T$ cannot uniquely define heterogeneously and homogeneously-dominated regimes, and, parameterizations using such approaches are inherently limited. It was shown that the contribution of each freezing mechanism to crystal number concentration, depends only on $\frac{N_{\mathrm{IN}}}{N_{\mathrm{Iim}}}$. By providing an expression for $N_{\mathrm{lim}}$, the need for defining "dominant" regimes of ice formation is eliminated.

When evaluated over a wide range of conditions, the new parameterization reproduced the results of the detailed numerical solution of the parcel model equations, with an average error of $6 \pm 33 \%$, which is remarkable low given the complexity and nonlinearity of Eqs. (5) to (7). The new parameterization also compares favorably against other 

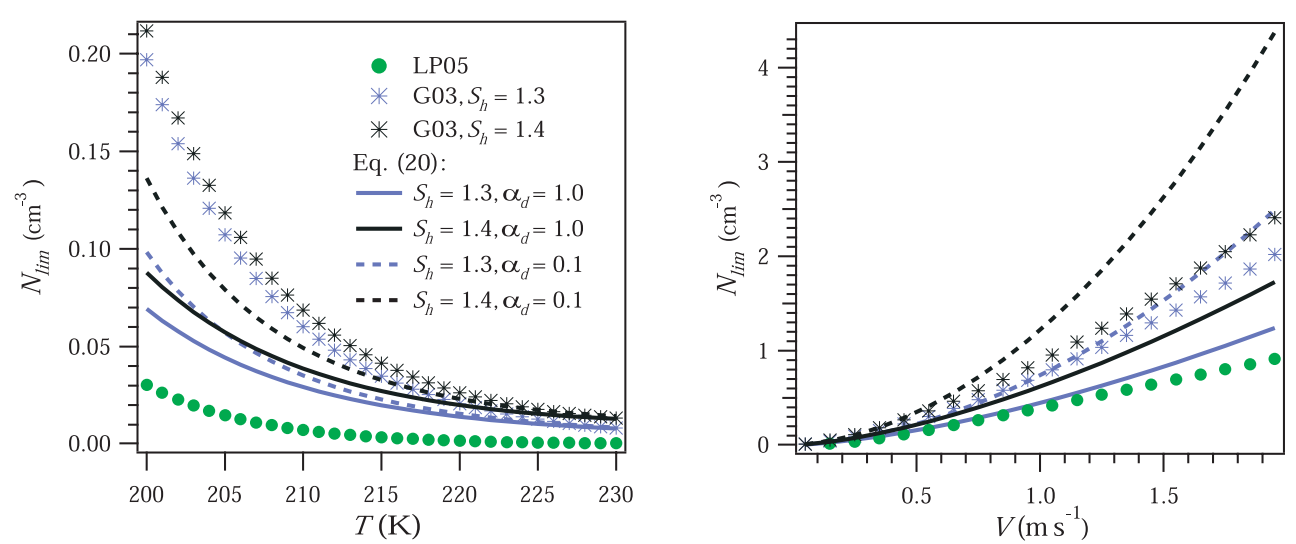

Fig. 6. $N_{\lim }$ vs. $T$ at $V=0.1 \mathrm{~m} \mathrm{~s}^{-1}$ (left panel) and $N_{\lim }$ vs. $V$ at $T=215 \mathrm{~K}$ (right panel), calculated using the parameterizations of Gierens (2003 , G03), Liu and Penner (2005, LP05), and Eq. (20).

formulations (which require numerical integration). The approach presented here overcomes common difficulties in including the competition between homogeneous and heterogeneous modes in large scale models. In this study we assumed a single type, monodisperse, chemically uniform, IN population. Multiple IN populations and freezing modes that reflect cirrus formation for atmospheric relevant aerosol is the focus of a future study. Even though much work still remains to be done on the prediction of IN concentrations and freezing thresholds, this work offers a computationally efficient and rigorous approach to include such knowledge in atmospheric and cloud models, once available.

\section{Appendix A}

A summary of parameters developed for the BN08 parameterization is provided here. The effective growth parameter in Eq. (1) is defined as

$\bar{\Gamma}=\frac{\int_{\bar{D}_{o}}^{D c, s_{\max }} \frac{D_{c}}{\Gamma_{1} D_{c}+\Gamma_{2}} d D_{c}}{D_{c, s_{\max }}-\bar{D}_{o}}=\frac{\gamma}{\Gamma_{1}}\left[1+\frac{\Gamma_{2}}{\Gamma_{1}} \frac{\ln \left(\frac{\Gamma_{2}+\Gamma_{1} D_{c, s_{\max }}}{\Gamma_{2}+\Gamma_{1} \bar{D}_{o}}\right)}{D_{c, s_{\max }}-\bar{D}_{o}}\right]$

where $\gamma=1.33$, and $D_{c, s_{\max }}$ is the maximum size reached by the homogeneously nucleated ice crystals, given by

$D_{c, s_{\max }}=\min \left\{\left(1.6397 \times 10^{-14} T-3.1769 \times 10^{-12}\right)\right.$

$\left.V^{-0.05}\left(N_{o} D_{g, \text { dry }}^{3}\right)^{-0.373} ; 10^{-4}\right\}$

with $V$ is in $\mathrm{m} \mathrm{s}^{-1}, T$ is in $\mathrm{K}, N_{o}$ in $\mathrm{cm}^{-3}$, and $D_{g \text {,dry }}$ in $\mathrm{m}$.

The parameter, $k(T)$ in Eq. (1) is defined as $k(T)=\frac{\ln \left[J\left(S_{i}\right) / J\left(S_{\max }\right)\right]}{S_{i}-S_{\max }}$. For the purposes of this study we fit $k(T)$ to the data of Koop et al. (2000) for $J$ between $10^{8}$ and $10^{22} \mathrm{~m}^{-3} \mathrm{~s}^{-1}$ :

$k(T)=0.0240 T^{2}-8.035 T+934.0$ with $T$ in $\mathrm{K}$.

$S_{\max }$ is obtained by solving $J\left(S_{\max }\right)=10^{16} \mathrm{~s}^{-1} \mathrm{~m}^{-3}$ (Koop et al., 2000), using the analytical fit of Ren and Mackenzie (2005).

\section{Appendix B}

\section{List of symbols}

A $\quad y_{\max }\left(y_{\max }-2\right)$, defined in Eq. (11)

$\alpha \quad \frac{g \Delta H_{s} M_{w}}{c_{p} R T^{2}}-\frac{g M_{a}}{R T}$

$\beta \quad \frac{M_{a} p}{M_{w} p_{i}^{o}}$

$\alpha_{d} \quad$ Water vapor to ice deposition coefficient

$c_{p} \quad$ Specific heat capacity of air

$\Delta H_{S} \quad$ Specific heat of sublimation of water

$D_{c, s_{\max }} \quad$ Equivalent diameter of the largest homogeneously frozen ice particle at $S_{\max }$

$D_{c} \quad$ Volume sphere-equivalent diameter of an ice particle

$D_{c, \text { IN }} \quad$ Volume sphere-equivalent diameter of an IN-frozen crystal

$D_{g, \text { dry }} \quad$ Geometric mean diameter of the dry aerosol size distribution

$D_{\lim } \quad$ Limiting size of the IN-frozen crystals

$D_{\text {max,IN }}$ Equivalent diameter of the IN-frozen ice crystals at $S_{\max }$

$\bar{D}_{o} \quad$ Average diameter of the supercooled liquid droplet population 


\begin{tabular}{|c|c|}
\hline$D_{o, \mathrm{IN}}$ & Initial size of the IN at the point of freezing \\
\hline$D_{v}$ & Water vapor diffusion coefficient \\
\hline$\Delta S_{h}$ & $S_{\max }-S_{h}$ \\
\hline$\Delta S_{h}^{*}$ & Growth integral defined in Eq. (15) \\
\hline$f_{c}, f_{c, \mathrm{IN}}$ & $\begin{array}{l}\text { Fraction of frozen particles at } S_{\max } \text { with } \\
\text { and without IN present, respectively. }\end{array}$ \\
\hline$g$ & Acceleration of gravity \\
\hline $\bar{\Gamma}$ & $\begin{array}{l}\text { Effective growth parameter defined in } \\
\text { Eq. (A1) }\end{array}$ \\
\hline$\Gamma\left(D_{o, \mathrm{IN}}\right)$ & $\frac{\Gamma_{1}}{2} D_{o, \mathrm{IN}}^{2}+\Gamma_{2} D_{o, \mathrm{IN}}$ \\
\hline$\Gamma_{1}$ & $\frac{\rho_{i} R T}{4 p_{i}^{o} D_{v} M_{w}}+\frac{\Delta H_{s} \rho_{i}}{4 k_{a} T}\left(\frac{\Delta H_{s} M_{w}}{R T}-1\right)$ \\
\hline$\Gamma_{2}$ & $\frac{\rho_{i} R T}{2 p_{i}^{o} M_{w}} \sqrt{\frac{2 \pi M_{w}}{R T}} \frac{1}{\alpha_{d}}$ \\
\hline K & Curvature constant defined in Eq. (10) \\
\hline$k(T)$ & $\begin{array}{l}\text { Homogeneous freezing parameter defined } \\
\text { in Eq. (A3) }\end{array}$ \\
\hline$k_{a}$ & Thermal conductivity of air \\
\hline$M_{w}, M_{a}$ & Molar masses of water and air, respectively \\
\hline$N_{c}$ & Ice crystal number concentration \\
\hline$N_{\text {IN }}$ & $\begin{array}{l}\text { Number concentration of the IN } \\
\text { population }\end{array}$ \\
\hline$N_{\lim }$ & $\begin{array}{l}\text { Limiting } N_{\text {IN }} \text { that would prevent } \\
\text { homogeneous nucleation }\end{array}$ \\
\hline$N_{o}$ & $\begin{array}{l}\text { Number concentration of the supercooled } \\
\text { liquid droplet population }\end{array}$ \\
\hline$O\left(y, y^{2}, \ldots\right)$ & High order terms in Eq. (10) \\
\hline$p$ & Ambient pressure \\
\hline$p_{i}^{o}$ & Ice saturation vapor pressure \\
\hline$\rho_{i}, \rho_{a}$ & Ice and air densities, respectively \\
\hline$R$ & Universal gas constant \\
\hline$S_{i}$ & $\begin{array}{l}\text { Water vapor saturation ratio with respect } \\
\text { to ice }\end{array}$ \\
\hline$S_{\max }$ & $\begin{array}{l}\text { Maximum ice saturation ratio; } \\
\text { homogeneous freezing threshold }\end{array}$ \\
\hline$S_{h}$ & Freezing threshold of the IN population \\
\hline$\dot{S}_{\max , \mathrm{IN}}$ & $\begin{array}{l}\text { Rate of change of } S_{i} \text { at } S_{\max } \text { with IN } \\
\text { present }\end{array}$ \\
\hline$\dot{S}_{h}$ & Rate of change of $S_{i}$ at $S_{h}$ \\
\hline$T$ & Temperature \\
\hline
\end{tabular}

$\begin{array}{ll}T_{o} & \text { Initial temperature } \\ t & \text { Time } \\ V & \text { Updraft velocity } \\ w_{\text {IN }} & \begin{array}{l}\text { Ice mass mixing ratio of the } \\ \text { heterogeneously frozen crystals }\end{array} \\ x, y & \begin{array}{l}\text { Dimensionless variables defined in } \\ \text { Eqs. (8) and (9) }\end{array} \\ y_{\max } & \text { Value of } y \text { at } x=1\end{array}$

Acknowledgements. This study was supported by NASA MAP and a NASA New Investigator Award.

Edited by: T. Koop

\section{References}

Abbatt, J. P. D., Benz, S., Cziczo, D. J., Kanji, Z., and Möhler, O.: Solid ammonium sulfate as ice nuclei: a pathway for cirrus cloud formation, Science, 313, 1770-1773, 2006.

Archuleta, C. M., DeMott, P. J., and Kreidenweis, S. M.: Ice nucleation by surrogates for atmospheric mineral dust and mineral dust/sulfate particles at cirrus temperatures, Atmos. Chem. Phys., 5, 2617-2634, 2005, http://www.atmos-chem-phys.net/5/2617/2005/.

Baker, M. B. and Peter, T.: Small-scale cloud processes and climate, Nature, 451, 299-300, 2008.

Barahona, D. and Nenes, A.: Parameterization of cirrus formation in large scale models: Homogenous nucleation, J. Geophys. Res., 113, D11211, doi:11210.11029/12007JD009355, 2008.

Beaver, M. R., Elrod, M. J., Garland, R. M., and Tolbert, M. A.: Ice nucleation in sulfuric acid/organic aerosols: Implications for cirrus cloud formation, Atmos. Chem. Phys., 6, 3231-3242, 2006, http://www.atmos-chem-phys.net/6/3231/2006/.

Cantrell, W. and Heymsfield, A. J.: Production of ice in tropospheric clouds, B. Am. Meteorol. Soc., 86, 795-807, 2005.

Chen, Y., Kreidenweis, S. M., McInnes, L. M., Rogers, D. C., and Demott, P. J.: Single particle analyses of ice nucleating aerosols in the upper troposphere and lower stratosphere, Geophys. Res. Lett., 25, 1391-1394, 1998.

Chen, Y., DeMott, P. J., Kreidenweis, S. M., Rogers, D. C., and Sherman, D. E.: Ice formation by sulfate and sulfuric acid aerosol particles under upper-tropospheric conditions, J. Atmos. Sci., 57, 3752-3766, 2000.

Cozic, J., Verheggen, B., Mertes, S., Connolly, P., Bower, K., Petzold, A., Baltensperger, U., and Weingartner, E.: Scavenging of black carbon in mixed phase clouds at the high alpine site Jungfraujoch, Atmos. Chem. Phys. Discuss., 6, 11 877-11 912, 2006, http://www.atmos-chem-phys-discuss.net/6/11877/2006/.

Cziczo, D. J. and Abbatt, J. P. D.: Ice nucleation in $\mathrm{NH}_{4} \mathrm{HSO}_{4}$, $\mathrm{NH}_{4} \mathrm{NO}_{3}$, and $\mathrm{H}_{2} \mathrm{SO}_{4}$ aqueous particles: Implications for cirrus formation, Geophys. Res. Lett., 28, 963-966, 2001.

DeMott, P. J., Meyers, M. P., and Cotton, R. W.: Parameterization and impact of ice initiation processes relevant to numerical model simulations of cirrus clouds, J. Atmos. Sci., 51, 77-90, 1994. 
DeMott, P. J., Rogers, D. C., and Kreidenweis, S. M.: The susceptibility of ice formation in upper tropospheric clouds to insoluble aerosol components, J. Geophys. Res., 102, 19575-19584, 1997.

DeMott, P. J., Rogers, D. C., Kreidenweis, S. M., Chen, Y., Twohy, C. H., Baumgardner, D. G., Heymsfield, A. J., and Chan, K. R.: The role of heterogeneous freezing nucleation in upper tropospheric clouds: Inferences from SUCCESS, Geophys. Res. Lett., 25, 1387-1390, 1998.

DeMott, P. J., Cziczo, D. J., Prenni, A. J., Murphy, D. M., Kreidenweis, S. M., Thompson, D. S., Borys, R., and Rogers, D. C.: Measurements of the concentration and composition of nuclei for cirrus formation, Proc. Natl. Acad. Sci. USA, 100, 14655 14 660, 2003a.

DeMott, P. J., Sassen, K., Poellot, M. R., Baumgardner, D. G., Rogers, D. C., Brooks, S. D., Prenni, A. J., and Kreidenweis, S. M.: African dust aerosols as atmospheric ice nuclei, Geophys. Res. Lett., 30, 1732, doi:1710.1029/2003GL017410, 2003b.

Field, P. R., Möhler, O., Connolly, P., Krämer, M., Cotton, R., Heymsfield, A. J., Saathoff, H., and Schnaiter, M.: Some ice nucleation characteristics of Asian and Saharan desert dust, Atmos. Chem. Phys., 6, 2991-3006, 2006, http://www.atmos-chem-phys.net/6/2991/2006/.

Fridlind, A. M., Ackerman, A. S., Jensen, E. J., Heymsfield, A. J., Poellot, M. R., Stevens, D. E., Wang, D., Miloshevich, L. M., Baumgardner, D. G., Lawson, P., Willson, J., Flagan, R. C., Seinfeld, J. H., Jonsson, H. H., VanReken, T. M., Varutbangkul, V., and Rissman, T. A.: Evidence for the predominance of midtropospheric aerosols as subtropical anvil cloud nuclei, Science, 304, 718-722, 2004.

Gayet, J. F., Ovarlez, J., Shcherbakov, V., Ström, J., Schumann, U., Minikin, A., Auriol, F., Petzold, A., and Monier, M.: Cirrus cloud microphysical and optical properties at southern and northern midlatitudes during the INCA experiment, J. Geophys. Res., 109, D20206, doi:20210.21029/22004JD004803, 2004.

Gierens, K.: On the transition between heterogeneous and homogeneous freezing, Atmos. Chem. Phys., 3, 437-446, 2003, http://www.atmos-chem-phys.net/3/437/2003/.

Haag, W., Kärcher, B., Strom, J., Minikin, A., Lohmann, U., Ovarlez, J., and Stohl, A.: Freezing thresholds and cirrus formation mechanisms inferred from in situ measurements of relative humidity, Atmos. Chem. Phys., 3, 1791-1806, 2003, http://www.atmos-chem-phys.net/3/1791/2003/.

Hartmann, D. L., Holton, J. R., and Fu, Q.: The heat balance of the tropical tropopause, cirrus, and stratospheric dehydration, Geophys. Res. Lett., 28, 1969-1972, 2001.

Heymsfield, A. J. and Sabin, R. M.: Cirrus crystal nucleation by homogenous freezing of solution droplets., J. Atmos. Sci., 46, 2252-2264, 1989.

Heymsfield, A. J., Miloshevich, L. M., Twohy, C. H., Sachse, G., and Oltmans, S.: Upper-tropospheric relative humidity observations and implications for cirrus ice nucleation, Geophys. Res. Lett., 25, 1343-1346, 1998.

Hung, H., Malinowski, A., and Martin, S. T.: Kinetics of heterogeneous ice nucleation on the surfaces of mineral dust cores inserted into aqueous ammonium sulfate particles, J. Phys. Chem. A, 107, 1296-1306, 2003.

Kärcher, B. and Lohmann, U.: A parameterization of cirrus cloud formation: Heterogeneous freezing, J. Geophys. Res., 108, 4402,
doi:10.1029/2002JD003220, 2003.

Kärcher, B., Hendricks, J., and Lohmann, U.: Physically based parameterization of cirrus cloud formation for use in global atmospheric models, J. Geophys. Res., 111, D01205, doi:01210.01029/02005JD006219, 2006.

Kärcher, B., Mohler, O., DeMott, P. J., Pechtl, S., and Yu, F.: Insights into the role of soot aerosols in cirrus cloud formation, Atmos. Chem. Phys., 7, 4203-4227, 2007, http://www.atmos-chem-phys.net/7/4203/2007/.

Khvorostyanov, V. I. and Sassen, K.: Toward the theory of homogeneous nucleation and its parameterization for cloud models, Geophys. Res. Lett., 25, 3155-3158, 1998.

Khvorostyanov, V. I. and Curry, J. A.: The theory of ice nucleation by heterogeneous freezing of deliquescent mixed CCN. Part I: critical radius, energy and nucleation rate, J. Atmos. Sci., 61, 2676-2691, 2004.

Khvorostyanov, V. I. and Curry, J. A.: The theory of ice nucleation by heterogeneous freezing of deliquescent mixed CCN. Part II: parcel model simulations, J. Atmos. Sci., 62, 261-285, 2005.

Koop, T., Luo, B., Tslas, A., and Peter, T.: Water activity as the determinant for homogeneous ice nucleation in aqueous solutions, Nature, 406, 611-614, 2000.

Lin, R., Starr, D., DeMott, P. J., Cotton, R., Sassen, K., Jensen, E. J., Kärcher, B., and Liu, X.: Cirrus parcel model comparison project. Phase 1: The critical components to simulate cirrus initiation explicitly, J. Atmos. Sci., 59, 2305-2328, 2002.

Liou, K.: Influence of cirrus clouds on weather and climate processes: a global perspective, Mon. Weather Rev., 114, 11671199, 1986.

Liu, X. and Penner, J. E.: Ice nucleation parameterization for global models, Meteorol. Z., 14, 499-514, 2005.

Lohmann, U., Kärcher, B., and Hendricks, J.: Sensitivity studies of cirrus clouds formed by heterogeneous freezing in the ECHAM GCM, J. Geophys. Res., 109, doi:10.1029/2003JD004443, 2004

Marcolli, C., Gedamke, S., Peter, T., and Zobrist, B.: Efficiency of immersion mode ice nucleation on surrogates of mineral dust, Atmos. Chem. Phys., 7, 5081-5091, 2007, http://www.atmos-chem-phys.net/7/5081/2007/.

Minnis, P.: Contrails, cirrus trend, and climate, J. Climate, 17, 1671-1685, 2004.

Möhler, O., Büttner, S., Linke, C., Schnaiter, M., Saathoff, H., Stetzer, O., Wagner, R., Krämer, M., Mangold, A., Ebert, V., and Schurath, U.: Effect of sulfuric acid coating on heterogeneous ice nucleation by soot aerosol particles, J. Geophys. Res., 110, D11210, doi:11210.11029/12004JD005169, 2005.

Möhler, O., DeMott, P. J., Vali, G., and Levin, Z.: Microbiology and atmospheric processes: the role of biological particles in cloud physics Biogeosciences, 4, 1059-1071, 2007, http://www.biogeosciences.net/4/1059/2007/.

Monier, M., Wobrock, W., Gayet, J. F., and Flossman, A.: Development of a detailed microphysics cirrus model tracking aerosol particles histories for interpretation of the recent INCA campaign, J. Atmos. Sci., 63, 504-525, 2006.

Penner, J. E., Lister, D. H., Griggs, D. J., Dokken, D. J., and McFarland, M.: Aviation and the global atmosphere - A special report of IPCC working groups I and III. Intergovernmental Panel on Climate Change, Cambridge University Press, 365 pp., 1999.

Prenni, A. J., DeMott, P. J., Twohy, C. H., Poellot, M. R., Kreidenweis, S. M., Rogers, D. C., Brooks, S. D., Richardson, M. 
S., and Heymsfield, A. J.: Examinations of ice formation processes in Florida cumuli using ice nuclei measurements of anvil ice crystal particle residues, J. Geophys. Res., 112, D10121, doi:10110.11029/12006JD007549, 2007.

Pruppacher, H. R. and Klett, J. D.: Microphysics of clouds and precipitation 2nd ed., Kluwer Academic Publishers, Boston, MA, 1997.

Ren, C. and Mackenzie, A. R.: Cirrus parameterization and the role of ice nuclei, Q. J. Roy. Meteorol. Soc., 131, 1585-1605, 2005.

Sassen, K., DeMott, P. J., Prospero, J. M., and Poellot, M. R.: Saharan dust storms and indirect aerosol effects on clouds: CRYSTAL-FACE results, Geophys. Res. Lett., 30, 1633, doi:1610.1029/2003GL017371, 2003.

Seinfeld, J. H.: Clouds, contrails and climate, Nature, 391, 837838, 1998.

Stuber, N., Forster, P., Radel, G., and Shine, K.: The importance of the diurnal and annual cycle of air traffic for contrail radiative forcing, Nature, 441, 864-867, 2006.

Tabazadeh, A., Martin, S. T., and Lin, J.: The effect of particle size and nitric acid uptake on the homogeneous freezing of aqueous sulfuric acid particles, Geophys. Res. Lett., 27, 1111-1114, 2000.
Vali, G.: Freezing rate due to heterogeneous nucleation, J. Atmos. Sci., 51, 1843-1856, 1994.

Zobrist, B., Marcolli, C., Koop, T., Luo, B., Murphy, D. M., Lohmann, U., Zardini, A., Krieger, U. K., Corti, T., Cziczo, D. J., Fueglistaler, S., Hudson, P. K., and Peter, T.: Oxalic acid as a heterogeneous ice nucleus in the upper troposphere and its indirect aerosol effect, Atmos. Chem. Phys., 6, 3115-3129, 2006, http://www.atmos-chem-phys.net/6/3115/2006/.

Zobrist, B., Koop, T., Luo, B., Marcolli, C., and Peter, T.: Heterogeneous ice nucleation rate coefficient of water droplets coated by a nonadecanol monolayer, J. Phys. Chem. C, 111, 2149-2155, 2007.

Zobrist, B., Marcolli, C., Peter, T., and Koop, T.: Heterogeneous ice nucleation in aqueous solutions: the role of water activity, J. Phys. Chem. A., 112, 3965-3975, 2008.

Zuberi, B., Bertram, A. K., Cassa, C. A., Molina, L. T., and Molina, M. J.: Heterogeneous nucleation of ice in (NH4)2SO4-H2O particles with mineral dust immersions, Geophys. Res. Lett., 29, 1504, doi:1510.1029/2001GL014289, 2002. 